\title{
IDENTITY DISCLOSURE AND INFORMATION SHARING IN DONOR CONCEPTION REGIMES: THE UNFULFILLED POTENTIAL OF VOLUNTARY REGISTERS
}

Jenni Millbank ${ }^{1}$

This article has been accepted for publication in International Journal of Law, Policy and the Family (C) Jenni Millbank 2014. All rights reserved.

\begin{abstract}
This article explores the scope and effectiveness of formal donor identity registers currently in operation in assisted conception regimes in Australia and the UK. In particular, it examines the function of voluntary registers which are intended to fill the gaps left by 'central' identity registers which mandate timed release of donor identity on request of donor conceived adults. There are three 'gaps' left by central registers identified here: conceptions which took place prior to the operation of the relevant registers; parents and offspring who desire access to identifying information or a means of making contact prior to the age set for information release under current registers; and parents and offspring who desire information not available under current registers, specifically, identifying information or a means of making contact with other offspring from the same donor. The article reflects on interviews with a set of 21 parents who had undertaken donor conception in Australia through licensed IVF treatment concerning their understandings of disclosure regimes and wishes for, and experience of, seeking information and contact.
\end{abstract}

\section{INTRODUCTION}

This article explores the scope and effectiveness of formal donor identity registers currently in operation in assisted conception regimes in Australia and the UK. In undertaking this analysis, the article reflects on interviews with 21 parents who had undertaken donor conception in Australia through licensed IVF treatment, concerning their understandings of disclosure regimes and wishes for, and experience of, seeking information and contact.

In this article I use 'open disclosure' broadly to refer to legal and cultural contexts in which identity disclosure donors are mandated and parental openness about donor conception is prioritised, encouraged and facilitated, for example via ethical guidance and clinical licensing conditions. This is presently true of both the UK and Australia. ${ }^{1}$ While I contest the vein of genetic determinism which blurs information and family relationships in some of the policy and scholarly debate (on this see: Leighton 2012; 2013), my view is that open disclosure is a vital pre-requisite to enable donor conceived people to make their own choices about accessing information and to form their own meanings and connections regarding genetic links. As the Nuffield Council put it,

It is not the case that all prospective parents, parents and donor-conceived people will find information about the donor meaningful or useful ... The extent to which information is wanted, or indeed found to be essential, will depend entirely on the

\footnotetext{
${ }^{ \pm}$Professor of Law, University of Technology, Sydney. This research was supported by Discovery Project Grant 0986213 from the Australian Research Council and UTS: Law. Thanks to Sonia Allan, Eric Blyth, Kate Bourne, Karin Hammarberg, Louise Johnson, Isabel Karpin and Anita Stuhmcke for their thoughtful comments on earlier drafts.
} 
individuals concerned. While the state, in its stewardship role, has a duty to ensure that information is available for those who might feel an interest in or need for it, this duty should not be interpreted as an endorsement of the position that people affected by donor conception must or necessarily do want or need it (Nuffield Council on Bioethics, 2013: [6.30] emphasis in original).

In this article I use the term 'identity disclosure regime' to refer broadly to legislated systems which require and facilitate the release of the donor's identity at the request of the donor conceived person. 'Formal registers' are those established by law and 'central registers' are those held by government departments in which record-keeping on donor conceptions and identity is centralised. Identity disclosure regimes in various jurisdictions differ in many respects (see Blyth and Firth 2009; Allan 2012a), but broadly speaking do the following: record information on donor conceived individuals and donors; mandate release of donor identity at the request of donor conceived individuals who have reached a set age; operate prospectively (meaning they only cover children conceived after the introduction of such laws, with disclosure planned for a period commencing some 18 or more years later). I use 'parents' or 'recipient parents' interchangeably to refer to gamete donation recipients who are raising or have raised a donor conceived child and 'offspring' to refer to the donor conceived individual who may be either a child ('minor offspring') or an adult. When referring to offspring-offspring contact I mean contact between genetic half siblings from the same donor, rather than children born into the donor's own family.

There are three 'gaps' left by central registers identified here: conceptions which took place prior to the commencement of the relevant registers; parents and offspring who desire access to identifying information or a means of making contact prior to the minimum age set for information release under current registers; and parents and offspring who desire other information not available under current registers, in particular, identifying information or a means of making contact with other offspring from the same donor. There are a number of other register 'gaps' not under discussion here, for example donors or children within the donor's own family who wish to access information or make contact with recipient parents or offspring.

Voluntary registers have been posed as a solution to the gaps left by central registers. However, their consensual basis means that administrators will only make a match or initiate contact if both parties have already joined; they will not actually invite someone who is not already on the register to join in order to make a match. The limitation of 'passive' registers is well illustrated by the litigation brought by Kimberly Springfield, a donor conceived person in the Australian state of Victoria who joined the formal voluntary register. Ms Springfield asked the relevant Registrar to either write to the donor to alert him to the fact that she was on the register and invite him to join, or to write a letter to the clinic which had provided treatment asking them to pass on a letter to the donor in the same terms. The Registrar took the view that her statutory power to 'publicise' the register did not authorise her to take either step. The relevant administrative tribunal subsequently held that it did not have the power to review the decision, leaving no recourse. ${ }^{2}$ Ms Springfield, consequently, is one of those advocating for retrospective identity disclosure laws (Turner 2011), 
along with other donor offspring and their parents who have also initiated court based challenges to the operation of identity disclosure rules in Australia, the UK, and elsewhere. ${ }^{3}$ The experience of another Victorian woman, Narelle Grech, offers a painful contrast, as she too spent many years searching for her donor, and likewise made numerous public statements and law reform submissions (Grech, 2011). When the Premier of Victoria learned that Ms Grech was terminally ill, he directly intervened to access the record, the donor agreed immediately to identity release and he and Ms Grech met (Tomazin, 2013).

There has been a noticeable increase in serious policy consideration being given to retrospective disclosure of donor identity in both the UK and Australia in recent times, although it has not actually occurred at the time of writing. In 2011, an Australian federal parliamentary inquiry considered the issue of retrospective access to identifying information as part of a broader inquiry into inconsistent access to information for donor conceived people across the various states and territories (Senate Legal and Constitutional Affairs References Committee, 2011: [3.56]-[3.66], 'Senate Report'). While it did not make a recommendation on this issue, the committee stated that it 'supports, in principle, the rights of donors to retain the anonymity that they were guaranteed when they agreed to donate' and suggested that a national voluntary register was the appropriate response ([7.26], [7.27]). In contrast, in 2012 a parliamentary inquiry in Victoria recommended the introduction of legislation to allow identification of donors from the era of anonymity in that state (Parliament of Victoria Law Reform Committee, 2012: Rec 1, 'Parliament of Victoria Report'), ${ }^{4}$ a recommendation both hailed and condemned as a 'world-first' in pursuit of the rights of donor conceived people (Pennings 2012; Allan 2012b). In the UK in 2013 the Nuffield Council on Bioethics issued a report on the ethical aspects of information sharing in donor conception, in which it considered a wide range of issues with identifying and non-identifying information within a framework that rejected 'competing rights' in favour of valuing interests and relationships (Nuffield Council, 2013). The Council concluded that,

in order for the interests of donor-conceived adults [from the era of anonymity seeking identifying information] to be furthered, the donor must be willing to engage in at least minimal contact. Yet such willingness is simply not something that can be created through legislation. Thus not only does retrospective legal change potentially damage the interests of some donors, it would also, in at least some cases, fail to achieve its objective of promoting the interests of donor-conceived adults (Nuffield Council, 2013: [6.55]).

As a result the Nuffield Council recommended that the government 'rather than regulating retrospectively for the removal of anonymity, should instead take action to increase awareness among past donors that a willingness on their part to become identifiable would be highly valued by some donor-conceived adults' ([6.56]). However this recommendation did not extend to direct contact with past donors to invite consensual registration as this was seen by the Council to be unjustified (except in cases of serious and treatable medical diagnosis) as it would raise 'serious concerns' about breaching confidentiality ([6.57]).

In 2013 the government of Victoria, following a separate confidential consultation with donors (Hammarberg et al, 2014), issued its response to the 2012 parliamentary inquiry. In the government 
response, the retrospective repeal of anonymity was rejected in terms quite similar to those used by the Nuffield Report: 'Seeking consent would increase the likelihood that donor-conceived individuals could gain access to relevant contemporaneous information about their donors' (Government of Victoria, 2013: 7). Instead the government determined upon a 'facilitative and relationship-focused model' involving the extension of an earlier 'active' consensual register: that is, one with direct and individualised outreach to donors once an application is made $(4,5)$. The Victorian Register for donor conceptions between 1988 and 1998 allows for identification of the donor upon application only with the donor's contemporaneous consent. From 2006 to 2009 this consent-based process occurred with specialist intermediary support, and from 2010 has continued from within a different government department, albeit with a dramatic reduction in support services. The Victorian government now proposes to extend this register to pre-1988 anonymous conceptions and to reintroduce specialist intermediary support and has tabled legislation to achieve this, which, if passed, will commence in June $2015 .^{5}$

Additionally, in 2013 a NSW Parliamentary Inquiry considered, and rejected, the retrospective removal of donor anonymity. The NSW Inquiry mirrored the language of the Nuffield Report in its use of 'needs and responsibilities' in rejecting a framework of competing 'rights' (NSW Parliament, 2013: [4.123]) and also reflected the conclusions of the Victorian government in recommending the introduction of an 'active' register and support services to enable consent-based release of information for those conceived before the introduction of the central register (Ibid, Recommendations 6 and 10). Thus, it could be said that recent consideration of access to information outside of the win/lose frame of litigation has contributed to the generation of more creative 'compromise' proposals.

This article first provides the context of the current study. It then outlines regimes governing identity disclosure in Australia and the UK, addressing in particular the scope and take-up rate of voluntary registers to date. The article then reflects on how the choices of interviewees in the present study were informed by the anticipation of identity disclosure and interviewee experiences of interactions with, and desires for, information sharing regimes. The article then outlines the unique experience of the 1988 Victorian consent based register to argue that more flexible, active and well supported voluntary registers are highly desirable.

\section{THE STUDY}

There are comparatively few recent studies of parents' experiences of seeking information or making contact with the donor or other families formed through the same donor (eg Scheib and Ruby, 2008; Freeman et al, 2009) and even fewer on the views or experiences of mature offspring (eg Mahlstedt et al, 2010; Beeson et al 2011; Jadva et al, 2010). Most of these studies were survey based and few have qualitative dimensions. Moreover, almost all were undertaken in the United States drawing upon users of the informal voluntary Donor Sibling Registry, with very limited research coming from a context in which 'parental disclosure is both advocated and practised' and 'where the donor identity is accessible' through formal registers (Blyth et al, 2012: 787). 
The participants in the current study were drawn from a larger empirical study of the impact of law and policy on in-vitro fertilisation (IVF) users in Australia with a particular focus on decision-making concerning stored embryos. ${ }^{6}$ Among a total of 54 interviewees were 21 who had received donor sperm and a further four who had received donated embryos. In this article I address only the views of the sperm donor recipients, with the addition of one embryo recipient whose embryos had themselves been created through donor sperm. The 21 interviewees included 20 women and one man, representing 19 families and comprised seven single women, five members of heterosexual couples and nine members of lesbian couples. Two heterosexual participants were interviewed as a couple as were two lesbian participants. Interview duration varied between 30 minutes to 90 minutes, with most lasting around one hour. Nineteen interviewees had children as a result of the donation at the time of the interview, ranging in age from a few months to 20 years, and the other two were pregnant at the time of interview. In semi-structured interviews, participants were asked how they came to select their donor, if they knew what the identity disclosure rules were that applied to them at the time they undertook treatment, and whether there were other kinds of information or contact that they desired.

The only couple to conceive with a known sperm donor were heterosexual, and the donor was a close friend of the male member of the couple: all others conceived with an unknown sperm donor. The pervasive use of unknown donors reflects the fact that the cohort had all undertaken IVF, and indeed several of them had entered the clinic system in order to access donor sperm. Known donors are more likely outside of the clinic context, although it is not possible to know what proportion of donor conception families are occurring within and outside of licensed processes. Conception with known donors, and donors who were previously unknown (for instance through advertisements or matching websites), are less likely to raise issues of identification and information exchange as participants have some form of direct contact and can negotiate these issues themselves; they are, however, more likely to raise other complex questions around role definition and the nature and intensity of on-going relationships (Smith, 2013; Zanghellini, 2012).

While the focus is on the views and experiences of adult participants in donor conception and does not directly draw on the views of offspring, I note at the outset that the participants actively anticipated children's future needs and both shaped and mediated those interests through their own actions. I do not accept a framework of 'competing rights' and oppositional placement of donors, (potential) parents and (potential) children's interests in assisted reproduction policy. My research works from the relational premise that the interests of parents and children are intertwined (Nuffield Council 2013, Chapter 5). This is not to suggest that offspring views and interests are unimportant; rather that children's rights or best interests, while proclaimed by virtually all who work in this field, are neither singular nor self-evident - demonstrated not least of all by the recent history of 'best interests' in assisted reproductive regulation, involving a complete reversal of policy in many jurisdictions over the space of 20 years, from anonymity and secrecy to open disclosure. 


\section{IDENTITY DISCLOSURE REGIMES}

Although in the UK there was centralised record keeping by the Human Fertilisation and Embryology Authority ('HFEA') concerning assisted reproduction from 1991, the information kept on donors was quite limited, and only expanded and made consistent through new regulations in 2004 (Blyth and Speirs 2004). Identity disclosure donors were required from 2005, with mandatory and voluntary registers established at the same time. ${ }^{7}$

In contrast to the UK, Australia offers a patchwork of variation across states and eras. From 1988 Victoria had a central government register with consensual disclosure of donor identity (and mandated identity disclosure at the behest of offspring a decade later), ${ }^{8}$ with an accompanying voluntary register since 1998 (extended in 2001 to include pre-1988 conceptions) (Johnson et al, 2012; Parliament of Victoria Report, 2012). Western Australia introduced a voluntary register in 2002 and a legislative regime for identity disclosure in 2004 (Reproductive Technology Council of Western Australia, 2013b). ${ }^{9}$ NSW introduced both a voluntary register and legislative regime for identity disclosure in $2010 .^{10}$ The prohibition of anonymous donation in Australia more broadly took effect under national ethics guidelines which imposed licensing standards requiring all clinics to only use gametes from donors who have consented to identity release from $2005,{ }^{11}$ the same year as the UK.

Thus three Australian states have government-held or 'central' registers, while individual clinics in the remainder still hold donor identity records and facilitate the process of information exchange and identification (as do clinics in legislated states, concerning records preceding the introduction of registers) in a process that is regulated through national ethics guidance. ${ }^{12}$ In 2011 the Senate Report recommended the establishment of a national donor register, but thus was rejected by the federal government on the basis that it lacked Constitutional power to do so (Australian Government, 2012). The centralised approach in the UK can therefore be usefully contrasted with the complex matrix of various state mandatory and voluntary registers and individual clinic information sharing and donor matching protocols in Australia, all of which entail differing scope and approaches.

\section{The Central Registers}

The mandatory registers under discussion all set a minimum age at which offspring may request identifying information about their donor. In Western Australia this is set at $16,{ }^{13}$ while in the UK, Victoria and NSW it is $18 .{ }^{14}$ The Victorian regime is unique in that it requires mandatory counselling for the applicant prior to the release of identifying information.

While the first Victorian central register provided access to identifying information by donor conceived individuals (conceived between 1988 and 1997) from 2006, it must be recalled that this can only occur with the contemporaneous consent of the donor. This first 'opening' of the central register can therefore be seen as operating in a manner more akin to a voluntary register, with one important difference: it involves active outreach to donors. Between 2006 and 2009, 43 matches were made (Johnson et al, 2012). The experience of an 'active' consent based register is very useful for developing consideration of future models for voluntary registers and will be discussed in detail below. 
Of the central registers under discussion, the release of identifying information on the donor at the request of donor conceived applicants will take place from 2016 in Victoria, 2020 in Western Australia, 2023 in the UK, and 2028 in NSW. Only some of these jurisdictions permit early access to identifying information in certain circumstances, and they do so with varying conditions of access. In Western Australia a parent may, after completing approved counselling, consent on their own or their child's behalf prior to the statutory age of $16 .{ }^{15}$ As at January 2014 (when the oldest child born under the register would be nine) there had been no applications under this provision (Harris, 2014). In Victoria it is donor offspring, not their parents, who may access the donor's identifying information before 18 (either with parental consent or with the recommendation of a counsellor that they are sufficiently mature to understand the consequences of disclosure. $)^{16}$ As at November 2013 (when the oldest of the offspring born under the register would be 15) there had been no requests made for information under this provision in Victoria (Russell, 2013). In addition there is provision for parents to apply for information from the central register with the donor's consent, ${ }^{17}$ and it was the experience of the Infertility Treatment Authority that this provision was much more frequently used (Bourne, 2013). In NSW identifying information on the donor is only available on the application of a parent in the limited circumstances that there is a very serious threat to the child's health. ${ }^{18}$

In the UK there is no allowance for early access to identifying information, although the Act does provide access to non-identifying information on the donor and on other offspring to donor conceived individuals over the age of 16 who were conceived from 1991 onwards (with more detailed information available for those conceived after 2005: see Nuffield Council, 2013: [2.5][2.13]). The donor may also apply for information on the number of offspring, sex and year of birth. Parents are granted access to this information through the administrative practice of the HFEA (although notably are not granted this right by statute) as well as to any other non-identifying information on the register. In the calendar year 2012 there were 183 requests for non-identifying information, of which 103 were made by parents, while there 66 applications by donors and 14 by donor conceived people (Thompson, 2013).

In 2004 Eric Blyth and Jennifer Speirs argued that a minimum age approach to central registers was unduly restrictive, and should be replaced with the approach of 'sufficient maturity' used in the Swedish disclosure regime, and consistent with medical decision-making for minors in the UK and Australia (Blyth and Speirs, 2004: 320; reiterated in Blyth and Firth, 2009). While I concur with this view, such a change may not be sufficient to capture the broader range of early contact desires, discussed below, where registration and contact appear to arise more commonly from the initiative of parents. Interestingly, the 'sufficient maturity' approach was adopted in 2007 by the National Ethics Guidelines in Australia. In the section entitled 'Provide donor-conceived persons with information about their donor' the guidelines state that clinics 'must' provide information, including identifying information on donors who have consented (either because they donated post 2005 when this was required, or donated earlier but had given consent since), 
provided that he or she has either reached the age of 18 years or acquired sufficient maturity to appreciate the significance of the request (including any implications for his or her younger siblings) (NHMRC Guidelines, 2007: [6.11]).

Thus, perversely, donor offspring in unlegislated states may have better access to information in some respects than those in states with formal registers, as some clinics provide access to a wider range of information and do so at an earlier date than the formal registers do. However this is not consistently so.

For most of the jurisdictions under discussion, the provision of associated counselling and intermediary support services alongside identity registers, such as 'implications counselling' prior to seeking information, and mediated information exchange or contact, is very limited (Nuffield Council, 2013: [6.38]. See also NSW Parliament, 2013: Recommendation 12).

While beyond the scope of this paper, the lack of these services may have a significant impact on the utility of registers as well as the quality of the experience of those who use them.

\section{The Failed Promise of Voluntary Registers}

All of the jurisdictions discussed above have introduced voluntary registers to augment the operation of central identity disclosure registers. The relationship between voluntary and central registers is confusing for a number of reasons. Some voluntary registers pre-date the operation of the relevant central register, while others cover overlapping time periods for the purposes of certain information not available through the central register. Furthermore in some jurisdictions such as Victoria and the UK more than one voluntary register or central register has been introduced to cover different time periods of conception, which are then either added alongside previous registers or consolidated with them. While some registers allow all participants in donor conception to join, others are limited so as to exclude, variously, parents, minor offspring, or offspring-offspring links.

In the UK a non-government body was funded through the Department of Health to run a voluntary register addressing conceptions that took place prior to central record keeping in 1991. (The HFEA encourages those who donated after 1991, but before the removal of anonymity in 2005 , to reregister as identifiable donors under the central register. ${ }^{19}$ ) UK 'Donor Link' ran from 2004 to 2013 (Crawshaw and Marshall, 2008) when its functions were transferred across to the National Gamete Donation Trust, which now runs the 'Donor Conceived Register'. At June 2012 UK Donor Link had 558 registrants or partial registrants and had made 41 matches; 6 between donors and offspring and 35 links between offspring (Crawshaw et al, 2013: 26, 29). When the transfer occurred, only those who were 'fully registered' (about half of the members) were contacted and asked whether they would consent to their information going across to the new register: of the 82 donors, 67 agreed to transfer and of 177 donor conceived people, 157 agreed to transfer. Following the transfer of functions, from April 2013 to December 2013 there were 18 new registrants, and one new match made between two offspring (Witjens, 2013). 
Between 2004 and 2009 the HFEA supported the release of 'donor codes' by clinics at the request of parents, who were then able to use this identifier to link informally with other families who had used the same donor. However this practice was discontinued following a review which found problems with the practice (for instance some codes were not unique to particular clinics, causing erroneous 'matches' and clinics were uncertain of whether they were required to release the codes) and recommended the use of a formal register (HFEA, 2009a; 2009b). Since April 2010, following 2008 amendments to Human Fertilisation and Embryology Act 1990 (UK) s 31ZE, the HFEA has administered the 'Donor Sibling Link' as a voluntary register available to all donor conceived individuals over the age of 18 who were conceived post-1991 wishing to make contact with other offspring from the same donor. By November 2013 there were 44 registrants on the Sibling Link Registry and no matches had been made (O'Toole, 2013). This register does not permit parents or minors to apply. The combined effect of these provisions is that there is no formal voluntary register in the UK which provides for early contact.

In NSW the voluntary register has been in place since $2010 .{ }^{20}$ Donors, donor conceived individuals over the age of 18 and, unusually, adult children from the donor's own family, may all register. Parents of donor conceived people may also apply for information about the donor, although they cannot themselves register. By February 2014 there were 19 donors and 17 donor conceived individuals on the voluntary register, with two inquiries by parents, and no matches made (McCallan 2014).

In Western Australia the voluntary register has been in place since 2002 and is open to donors, donor conceived individuals aged 18 and over, and the parents of donor conceived individuals who are under 18 (Reproductive Technology Council of Western Australia, 2013b). Thus donor conceived minors are excluded from the voluntary register. This is a strange anomaly of the West Australian system, given that 16 year olds are eligible to access the central register. Parents of donor conceived individuals over the age of majority are also excluded from the voluntary register, although Crawshaw notes that there is some discretion to leave parents on the register if offspring reach majority and do not register (Crawshaw, 2011: 10). Participants must undertake mandatory counselling before the release of identifying information. As of 30 June 2013 there were 180 registrants on the Western Australian voluntary register: 73 donors, 23 donor conceived adults (DCA), and 84 parents of donor conceived children. The first match (defined by the RTC as involving the release of identifying information, not just the match of parties and exchange of non-identifying information), was made in 2010, after the register had been in operation for eight years. By June 2013 there were 19 matches of whom only seven went on to have the required counselling and to subsequently make contact. Most matches, and all contact, was between parents and donors or between offspring.

TABLE 1: Number of links between participants in WA Voluntary Register

\begin{tabular}{|l|r|r|}
\hline $\begin{array}{l}\text { Number of links between } \\
\text { participants in WA Voluntary } \\
\text { Register to June 2013 }\end{array}$ & Matched & Contacted \\
\hline DCA and donor & 2 & 0 \\
\hline Parent and donor & 8 & 4 \\
\hline
\end{tabular}




\begin{tabular}{|l|r|r|}
\hline Half siblings & 9 & 3 \\
\hline & & $\mathbf{1 9}$ \\
\hline Total & $\mathbf{1 9}$ & $\mathbf{7}$ \\
\hline
\end{tabular}

Source: Reproductive Technology Council of Western Australia, 2013a: 21.

In Victoria the voluntary register has been in place since $1998 .{ }^{21}$ Donors, parents and offspring are all able to join and to link with each other, and relatives of both donors and donor conceived people are also able to join. As at June 2013 there were 429 people on the voluntary register (VARTA, 2013a: 13), ${ }^{22}$ with a total of 85 matches made. ${ }^{23}$ Detailed figures available to 2009 show that many more links were made between recipient parents and donors, and between recipient parents and other recipient parents than were made between donors and offspring.

TABLE 2: Number of links between participants in Victorian voluntary register

\begin{tabular}{|l|r|r|r|}
\hline $\begin{array}{l}\text { Links made through the Victorian voluntary } \\
\text { register to 31 Oct 2009 }\end{array}$ & \multicolumn{1}{|c|}{$\begin{array}{c}\text { Pre-1988 } \\
\text { parties }\end{array}$} & $\begin{array}{r}\text { Post-1988 } \\
\text { parties }\end{array}$ & Total \\
\hline Donor and donor-conceived individual & 12 & 1 & $\mathbf{1 3}$ \\
\hline Donor and recipient & 5 & 25 & $\mathbf{3 0}$ \\
\hline $\begin{array}{l}\text { Donor-conceived and donor-conceived (half- } \\
\text { sibling) }\end{array}$ & 2 & 0 & $\mathbf{2}$ \\
\hline Recipient and recipient & 0 & 13 & $\mathbf{1 3}$ \\
\hline $\begin{array}{l}\text { More complex links that may be across } \\
\text { different voluntary registers and may involve } \\
\text { more than two parties }\end{array}$ & $\begin{array}{r}\text { across both } \\
\text { registers }\end{array}$ & $\begin{array}{r}\text { across both } \\
\text { registers }\end{array}$ & $\mathbf{4}$ \\
\hline Total links on voluntary registers & & \multicolumn{2}{|c|}{} \\
\hline
\end{tabular}

Source: Parliament of Victoria, 2012, 131.

This trend continues in less detailed figures available concerning 2010 to $2013 .{ }^{24}$ In particular the Victorian voluntary register data suggests that parents are registering on behalf of their children and it is therefore likely that contact, if any, is being made as a family. Parents may wish to make first contact with the donor in order to be assured that he is a 'good person' in order to feel more confident that the experience will be a positive one if their child decided to pursue contact later on (Bourne, 2013).

These very limited figures support the view that, while initially envisaged as a means of providing some access to information for those not covered by prospective central registers, voluntary registers are attracting those who wish to make 'early contact'. In particular there is a noticeable trend for voluntary registers to be more utilised by parents than by donor conceived individuals, and to access information connecting offspring. This data provides important food for thought concerning voluntary registers which exclude parents.

Clinic practice in Australia in response to requests for information sharing on a consensual basis, in both legislated and unlegislated states (including access to information on previously anonymous donors, early access to information on identifiable donors, and information exchange between recipient families) has evolved considerably in recent years. It is impossible to know the scale or success of information exchange facilitated on an individual level by clinics in Australia as these records are not public and there is no reporting function for such activities. However it appears from 
the findings of other researchers concerning 'proactive professional activity' in donor-linking practice (Crawshaw, 2011), and reports of interviewees in the current study, that clinics are more likely than formal voluntary registers to be the first port of call for those seeking information or contact.

In 2007 the Australian National Ethics Guidelines were amended to include guidance on information release. The section on donation includes the introductory statement that,

Voluntary exchange of information between persons conceived using donated gametes, gamete donors and gamete recipients, with the consent of all parties, is desirable (NHMRC, 2007: 25).

The guidelines state that they establish a 'minimum level of information that should be accessible to participants in a donated gamete treatment program' and that any further information can only occur with 'the consent of all parties concerned or as specified by law' (NHMRC, 2007: 25). The guidelines go on to specifically address offspring requests for identifying information as follows,

When approached by a person who was conceived using donated gametes and who now seeks identifying information about his or her genetic parents, the clinic should examine the consent form of the gamete donor and proceed as follows:

- If the consent form does not include permission for release of identifying information (because the donation was made before the introduction of these guidelines and the gamete donor has not come forward in response to the public information campaign outlined in paragraph 6.1.3), the clinic should make an appropriate effort, consistent with the original consent document and the privacy rights of the donor, to contact the gamete donor and obtain his or her consent to the release of information.

- If the consent form includes permission for release of identifying information, the clinic may notify the donor and release the information to the person requesting the information ( NHMRC, 2007: [6.13.1], emphasis added).

The ambiguity here is in the words, 'consistent with the original consent document' - as this could be seen as only allowing clinics to contact donors who had expressly provided for such contact; or conversely as allowing for an attempt at communication with any donor whose original consent document had not expressly declined it. Many consent documents, particularly from earlier eras, made no provision at all for such future possibilities. The peak Australian body of infertility counsellors, ANZICA, subsequently developed guidelines for 'donor linking counselling' establishing guiding principles, framing the role of the intermediary and setting out the steps to be followed (Bowman, 2013; RTAC, 2011: 1-2). It is implicit in the ANZICA document that contact may be initiated with those who had not expressly authorised it in advance, and this is reflected in a recent submission from the Fertility Society of Australia supporting confidential 'outreach to donors in a sensitive manner' (Bowman, 2013; see also reports of specific clinics initiating outreach for donors from the pre-disclosure era: Parliament of Victoria, 2012: [3.2.2.2]; NSW Parliament, 2013: [5.52][5.54]). For information requests that pre-date identity release regimes, therefore, clinics may be more responsive than formal voluntary registers, in that some of them at least will undertake 'active' outreach. 
The NHMRC guidelines are more prescriptive concerning offspring-offspring requests in a manner that prevents active outreach without explicit advance authorisation:

When a clinic is approached by a person who was conceived using donated gametes and who now seeks identifying information about his or her genetic siblings or halfsiblings, it should check its register of consent for the release of such information (see paragraph 6.1.3) and proceed as follows:

- If consent has been registered by the siblings concerned, the information may be released.

- If consent has not been registered, clinics should not release identifying information or contact the siblings (NHMRC, 2007: [6.13.2], emphasis added).

As with a number of formal voluntary registers, the Australian National Ethics Guidelines do not countenance a role for parents making such requests on their own or their children's behalf. It is therefore unclear what approach, if any, should be taken to parent-parent contact, or parents desiring early contact or information exchange with the donor. Crawshaw noted from her 2010 Australian fieldwork that while some infertility counsellors provided 'very good quality services' in linking families with minor children 'some were actively discouraged from doing so by their employers' (Crawshaw, 2011: 4).

The Nuffield Council considered the 'apparent appetite' for early contact and noted the benefits of this occurring through licensed donor conception rather than acting as a driver for informal arrangements. However it stopped short of recommending amendments to allow for early access to information on a consent basis. Rather, it recommended that the National Donation Strategy Group 'should look specifically at the question of whether the potential benefits of early information exchange and possible contact between donors and donor conceived families would be sufficient to justify proposals to change the law to permit this' (Nuffield Council, 2013: [6.42]).

Research from a number of jurisdictions has suggested that lesbian-led families and single mothers by choice utilising assisted conception are not only more likely to disclose to children the means of their conception than heterosexual families, but to do so earlier. They also appear more likely than heterosexual families to seek information on other offspring families, and to a lesser extent, the donor, and to do so earlier than heterosexual couple recipients of donor sperm (Freeman et al, 2009; Beeson et al 2011; Hertz et al, 2013). As the numbers of single women and lesbian couples utilising licensed services increase, in response to the dismantling of legal and ethical barriers in the UK and various Australian jurisdictions, as well as increased social acceptance for same-sex families and assisted conception more broadly, it appears likely that demand for voluntary registers (in particular for those providing 'early contact' and recipient family linking) will increase.

Arguably the founding logic of revealing the linear progenitor-offspring link in identity registers has been displaced, or at the very least complicated, by a more diverse and lateral sense of new kinship relations, to which voluntary registers to date have largely not attended. The following sections highlight these forms of new kinship in parents' accounts of donor selection, experience of anonymity, and views and experiences of early contact with donors and other recipient families. 


\section{PARTICIPANT EXPERIENCES}

Although the interviewees' experiences in the current study traversed the Australian patchwork of regulation, almost all of the donation recipients had undertaken treatment in an 'open disclosure' context. Of the interviewees who conceived in the late 1980s and early 1990s in the era of anonymity it is striking that both families defied prevailing clinical advice favouring anonymity to disclose the fact of donor conception to their children early in life. Kat and Toby, a heterosexual couple interviewed together, so strongly believed in the importance of disclosure that they brought a challenge through their clinic's ethics committee to enable them to utilise a known sperm donor in their treatment. The donor was a close friend who had been known to their children throughout their lives. Thus, the only interviewee to have undertaken anonymous donor conception as a recipient was Gwen, a married woman who had treatment in the late 1980s. Gwen's experience (discussed in the following section) is particularly complex and insightful as she was both a recipient and a donor: two years after giving birth to triplets she was asked by her clinic to donate her remaining embryos for treatment of others, and did so.

For all other recipient interviewees, open disclosure was established as an expectation at the time of treatment, reinforced through the counselling and consent processes, and those with children old enough to understand had already told them about the circumstances of their conception. Thus, in contrast to studies from the UK and elsewhere, none of the 19 recipient families proposed to keep the fact of donation a secret from their children (Readings et al, 2011; HFEA 'Donation Review Annexes', 2011: 97).

\section{Identity Disclosure and Donor Selection}

Overwhelmingly, interviewees reflected that information about their donor's identity was an important resource for their child, regardless of their own views or feelings.

I think that's really good because if our son chooses to never know him then that's his choice and that's an option. But if he did desperately want to know the donor I think it'd be really awful if he didn't have that opportunity. So I think at the moment the way it is it's the best of both worlds. That you've got a choice and that's the main thing.

Olivia (heterosexual couple)

Beatrice was the recipient of donated embryos from a woman who was known to her, but the embryos had themselves been created from donated sperm by an unknown donor. Thus Beatrice was in the unusual position of having both a known and an unknown donor for the same child. While she had introduced her daughter to the woman who had donated the embryos and her children, and the adults and children had a warm on-going relationship in which the children, who were full genetic siblings, were regarded as 'like cousins', she expressed apprehension about the sperm donor.

I feel uncomfortable about the idea of her [getting in] touch with her genetic/sperm donor father. I feel - just not that I don't necessarily think it's not natural and I wouldn't help it in the way because I understand it's the best thing for her but not necessarily the best thing for me if you know - it's a different thing. I suppose you don't really want 
anything to rock your family dynamics and things like that. The only thing is and it's something my mother [said] ... The more people who love a child the better and so that you shouldn't restrict that so if genetic people want to have a role ... and want to love the child, it's only good for the child. You have to just see it like that. ... I accept I'm going to be uncomfortable when Peggy goes looking ... from a selfish point of view but it doesn't mean I'm not going to encourage it or support her in it. If it's the best thing for her and it's a matter of putting yourself to one side.

Beatrice (heterosexual couple)

The prospect of future identification of an unknown donor and the possibility of the child's later contact with that man was highly influential on recipients' choice of donor.

I think for us that made a real difference in terms of the kinds of things we wanted to know about the donor and the way we thought about them. Not because we imagine that necessarily, you know, our child is going to have some kind of important relationship with that person. But if our child does turn 18 and wants to look for her biological father and may be in contact with this person, we kind of felt we wanted to know something about him as a person. We wanted to know more than the fact that he was 5' 11" and had brown hair and, you know, we wanted to be able to say to the best of our ability we chose someone who we thought sounded like a nice person. So that was important I think.

Sam (lesbian couple)

Jacqui said that she and her female partner selected 'a good role model'. Lilac, a single mother, reported that, 'I wanted to have a sense of the person' and the donor she selected 'seemed to really be concerned about the child and thinking, in the way he answered the questions'. Virtually all interviewees reported choosing a donor who seemed like a 'good' person and one whose values were broadly in accord with their own, in the hopes that any future contact would be a positive experience for their child.

I really wanted someone who was very happy to go to lesbians and single women. I really wanted someone who specifically said that ... because I wanted my child to feel positive about her conception in as many possible ways as possible. ... What was the highest priority of all was what they said about why they were donating ... I wanted it to be someone that I felt that my daughter could create a positive image of without it being too fanciful and pie in the sky. I wanted it to start on a positive basis.

Danielle (single mother)

For some, consideration of their potential child's symbolic or actual relationship with the donor was explicitly raised or reinforced through the counselling process. Anne reported that her counsellor had advised, 'pick someone who you actually like because it will be easier to talk positively about them to your children, whatever they are. You want to choose someone that you would like them to actually meet.'

One recipient, Olivia, relayed that their initial choice of donor had been someone who looked like her husband. As she continued treatment and 'came to terms' with the prospect of being open with a resulting child, they later switched to a donor whose written profile they liked more, even though 
this resulted in a child who is clearly not the genetic child of her partner. For most of the interviewees, physical attributes of the donor were not prioritised. However, Rose and Scoot, both single mothers by choice elected donors who physically resembled their own families because they were concerned that their children feel a sense of belonging. For Scoot, 'they're already dealing with the fact that there's no father so that would be another barrier', while for Rose, 'if my daughter ended up looking completely different to the rest of us I thought that there would be more of an inclination for her to wonder about the other side'.

At the same time that the donor is represented as a figure of increasing importance - as a man that their child would 'very likely want to meet' (Anne, quoting her counsellor) - patients were presented with a very small range of local donors to select from. Eight women utilised sperm imported from the USA because their Australian clinic was unable to supply local sperm at the time of their treatment. (In addition respondents indicated that two major clinics did not provide donor sperm at all and would only treat them if they self-recruited a donor.) Women who had utilised international sperm were generally positive about the fact that they were able to choose from a larger pool of donors, with a broader and more detailed range of medical and social information about each man, and to 'reserve' a supply in order to be guaranteed the same donor for subsequent children. In contrast, one single mother, Lilac, proffered that she waited a considerable time for a local donor 'because I wanted it to be an easier process if the child ... wanted to know more about the donor' and because she valued the ethos of altruism in the Australian system and thought that the donor was more likely to have values akin to her own as a result.

Several interviewees expressed concern that identity disclosure regimes may not be able to live up to their promise, given all that may occur in the intervening years:

It did worry me when I thought if [the donor] dies, do they tell us. It would be just horrible to have gone through 18 years ... [waiting] ... or telling the child when they're old enough to know, you can definitely - then how would we turn around at 18 and say we're really sorry, we've just found out he died when you were $10 \ldots$ because you could be constructing this future which you can't deliver on.

Jacqui (lesbian couple)

\section{An Experience of Anonymity}

At the time of her treatment in the early 1990s Gwen was told 'height, blood group and eye colour' of her sperm donor: in retrospect she wished for much more information, particularly medical history. A few years later Gwen contacted a donor conception support group and was made aware that some other families had access to more information about their donor. As a result, she recontacted her clinic and sought information on both the sperm donor and the recipient couple of her donated embryos, about whom she knew nothing.

The lady that gave me the information remembered me ... it was sort of like, look, I'm doing you a favour a bit on the side, but here's the information [that the sperm donor was from another state and the donor's hobbies; the embryo recipients were from another state and gave birth to a girl with the last of the donated embryos]. 
Gwen noted that her now adult children showed little or no interest in knowing about the donor and that she herself had no interest in contact beyond thanking him and finding out about his own children, if any. Gwen's feeling about the girl born of her embryo donated was quite different: she acknowledged often wondering about the child and wanting to meet her. Gwen had placed herself on a formal voluntary contact register and included a letter indicating her openness to contact, thus far without any result.

\section{Early Contact with Donor}

One interviewee, Olivia, noted that both the child's interest in the kinds of information they want about their donor and their readiness for possible contact cannot be knowable in advance. Given that the driving principle of disclosure regimes is to serve children's potential need for information, she suggested that legislating a fixed age for such requests may fail this objective. While the 'sufficient maturity' approach to access to identifying information was not one raised in the interviews, Olivia's views seem to reflect this approach. Only two of the 19 recipient families (Gwen, and Kat and Toby) had children who had reached majority. Of those who had minor children, only one interviewee, Laurie, reported that it was her child who was initiating the quest.

Because my daughter's 10 at the moment, going on 18 almost. Like it's really interesting because particularly since the relationship split, she keeps saying, mum when can I contact my father? I keep saying to her, look this is out of my hands, we have to go to the clinic. The clinic - you can't contact the clinic until you're 18 and there is a process that's there and we'll see what happens. But she's quite adamant about this kind of stuff in terms of trying to get more information.

Laurie (separated lesbian couple) (emphasis added)

Laurie was not alone among interviewees in mistakenly believing that the relevant ethical or statutory disclosure regime allowing identification at a set age (16 or 18) actually prohibited it from occurring on a voluntary basis prior to that age. Options for information sharing through formal voluntary registers or through clinic facilitated processes were not well understood by participants in the study.

For all other interviewees, early contact with the donor was a process considered or initiated by the parents on behalf of, rather than in response to, their children's needs and interests. Several interviewees reported that the option of early contact with the donor was important to them. It was notable that these women consistently stated that this was not because they wished to build a close or on-going relationship with the donor, but rather to express their gratitude and to be certain of access to information or contact in the future should their child seek it.

Prior to having the baby, having contact with the donor wasn't important to me. But as soon as I had the baby it was like, well yeah, you know. I need to find out more. This child may need to know. The earlier contact the better as far as I was concerned because you know, you don't know what's going to happen.

Scoot (single mother) 
Danielle had been influenced by research literature from the era of anonymity on the distress of children who only discovered that they were donor conceived in their teenage years. As a consequence she experienced early contact with the donor as so important to her child's wellbeing that it was 'part of her responsibility as a parent'.

I wasn't particularly interested - from my point of view, I would be happy if I never met the donor but I know that my - anecdotally and also the research suggests that donor children who meet their donor early often have fewer adjustment problems later. From that point of view, I was really keen to facilitate contact. I was really nervous about it because it's a problem that I don't need in my life, if I can put it like that, trying to manage a relationship with someone that's, potentially, very fraught. Obviously, it's part of the responsibility of being a parent so I have to do it.

Danielle (single mother)

Several women in the study reported that ' 18 is too long to wait' for information and worried that contact details might be lost in the meantime.

I'm always intrigued about how they're going to track these people down, assuming they update their addresses. ... should a clinic be charged with what is really about administering a long term project? Who controls the records? What happens to the records? I certainly have been updating my [contact information]. Because the other thing is, I don't know what the processes are if the donor wants to contact us, I have absolutely no idea. Again there's been a complete lack of information and transparency about that process.

Laurie (separated lesbian couple)

Two women used the metaphor of the donor being 'hit by a bus' (see also Johnson et al, 2012: 816).

In the current study the desire for early contact was not universal. Some expressed a fear of making early contact in case the donor wanted to 'become' a parent; lesbians and single mothers in particular were not confident that legal regimes would support their continued autonomous parenting if that were to occur.

Well this donor actually said in the letter that he would have liked a letter from us when the child was born, when our child was born and that he would have been really happy to receive letters. But I have a fear about that actually. That children are so gorgeous that when - I always get worried that when the donor saw the child or just knowing that a child was out there that was theirs, it might change how they felt about donating sperm and change what they wanted - what sort of contact they wanted.

Jess (lesbian couple)

It was for this reason, and the 'horror stories' of relationships ending up in court that some (Mariana, Jess, Lilac) noted they had chosen to use an unknown but identifiable donor through licensed services rather than a donor known to them from the outset.

Three women had actually gone through their clinic's counselling process with a known donor before withdrawing when they realised that while they saw the connection to the donor as an 
important resource for their child, he saw himself as a co-parent. These experiences highlight the distinction which mothers drew between information and familial relationships:

I think ideally I would [have preferred] a known donor ... because I would like my child or any other children to have access to their history and not just from me but from the donor as well and if they feel they need to have contact with the donor to be able to do that. But I don't want that to cause conflict in the family ... I was just aware that ... when the child is there, feelings come up that aren't there before. That a known donor who doesn't want to be involved might want to be involved later on and that was an issue.

Lilac (single mother)

Another single mother interviewee, Rose, reported that she had considered but not joined an informal voluntary register run by a group she belonged to because she saw this as a decision to be made by her daughter at adulthood.

These mixed views, and anxieties, highlight the need for mediated contact options, including those that allow for the non-identifying exchange of information.

\section{Early Contact with Other Recipient Families}

Among interviewees, five women had joined voluntary formal and informal registers; of them four had done so in order to make contact with other recipient families while their children were still very young (ages $<3$ years). (The exception was Gwen, discussed above, who had conceived her now adult children in the era of anonymity.) The search for information was framed in a similar vein to those who sought early contact with the donor:

We swap photos, we talk about where our kids are up to and that's about it. It's a little bit too, like you know if he's going to be wondering what he looks like or where he comes from ... If he wants to know if, you know, if this sort of characteristic or this aspect of his face comes from his donor, at least he's got a bunch of other kids that he can look at and say oh well we look the same in this aspect, so that must be from the donor side of things. I think it's just the more information the better really.

Apple (single mother)

The four women with minor children who had joined voluntary registers were all single mothers by choice, a trend in keeping with the available research which suggests high rates of contact between single mother offspring families (Hertz and Mattes, 2011). Scoot and Danielle had both utilised local donors. Scoot was aware of three other families (two single women and one heterosexual couple), she had attempted contact with all and had responses from the two single mothers, but had met only one of them face to face. Danielle had made contact with only one other woman who had utilised the same donor as herself and was disappointed to find that she had not yet been successful in becoming pregnant. Apple and Anne, by contrast, had utilised imported sperm. Apple had made contact with six families and reported emailing 'every six months or so'. Anne had email contact through a group of 15 other families based in the US, whom she referred to as 'the extended family'. Anne also reported exchange of photos as an important part of the relationship which had led to her feeling 'attached' and she planned to meet in person with other families at a later point. 
Within this quest was a greater sense of common experience and stronger social dimensions than that expressed in desiring contact with donors, as women sought out similarly situated families as part of a broader quasi-familial network:

In the ideal world, I think it would be nice to all meet up and go to Disneyland or do something like that. Because they're scattered all over the US. For all of us to meet up and go somewhere or do something, make a holiday out of it, when they are, I don't know, maybe eight or nine or something. The other good thing is, because there's someone already older than us, [that child] will get the [identifying donor] information first. So we'll get it early basically.

Apple (single mother)

Parents pursued these connections because they felt the genetic link between their children was, or could be, important to the children. But they did not consider themselves to be family members as such, and struggled to articulate new categories of relation (see also Blyth, 2012). In addition to referring to the children as 'half siblings' they also referred to them as 'like cousins' or as 'special' siblings (see also Hertz and Mattes, 2011).

One of the other families, she started referring to my boys, to her daughter, as 'your special brothers'. So that was fine with me. You know, she's got her own brother but these are your special brothers. I hadn't been using that term but when she was using it I felt, okay, well she can be your special sister.

I don't know [the other offspring] well enough [to feel a particular connection]. Like if we saw them regularly and they were more involved in our lives and that, maybe I'd feel a strong connection in maybe a sense of love or protectiveness towards them. But you know, I love my godson and I don't see him a lot ... But these children, one of them I've met a couple of times so I haven't built a bond or anything with her. But the fact that she's my child's half sibling, there's a connection just in that, or an affection, I suppose. But it wouldn't be an affection of love at this point, if that makes sense.

Scoot (single mother)

Even Anne who repeatedly referred to the other offspring families as 'extended family' notably used the prefix 'the' rather than ' $m y$ '; thus when talking of her own parents and sister, or her children, she used 'my family', but when talking of the mothers and children in the offspring grouping said 'the extended family'.

As when considering early contact with donors, some interviewees were reluctant to make contact because 'God knows ... what sort of people they are' (Rose) and concerns that the relationship might be intrusive, such as if the other families 'wanted something':

say you're in contact with these people and one of them rings you and says hey Mariana, our child has leukaemia, or something, we want you to donate something of Libby's, or they want her to be tested for compatibility or ... Our child needs a kidney, give us one of Libby's. What do you say? ... I suppose we'd cross that bridge when we came to it. But as a parent I go I don't want to put my child at risk for someone I don't know.

Mariana (lesbian couple) 
In this construction other recipient families are and remain strangers ('someone I don't know') rather than undiscovered relations: the children are 'ours' and yours, not siblings or half siblings. Yet for the women who had joined sibling registers and made contact, the possible exchange of medical information and facilitating the flow of other forms of information across the group was seen as a positive benefit. For Apple and Anne this went further, as they had in fact discussed gamete exchange with other mothers who had offspring from the same donor in a way that suggests a new kind of family relation. When Apple wanted to have another child but found that there were no further supplies of sperm available from her donor, another recipient mother from the US offered a reserved supply that she no longer intended to use herself, and they were in discussion with the sperm bank about how to achieve this. Anne had initially considered donating her remaining embryos to an infertile friend but on discovering that she could not do so (by virtue of the donor having met the family limit), Anne was actively pursuing the idea that she 'might be able to donate within the family, within the extended family'. She expressed a preference for a local recipient family so that she would be accessible should any offspring desire contact with her.

\section{An Experience of Inadvertent Contact, and Withdrawal of Contact}

One recipient who had undertaken treatment in a major clinic utilising an ethnic minority donor had the unusual experience of meeting another recipient family by chance. While undertaking treatment in the hopes of having a second child, Laurie and her then partner saw a distant acquaintance of her partner's in the waiting room. The acquaintance was of the same ethnic minority and was also undertaking treatment in the hopes of having a second child. It quickly became apparent in conversation that the two families had used the same donor. The families met and the two girls, who were less than a year apart in age, got on very well.

it's that classic, rather clichéd thing of long lost biological relatives who've discovered each other and find they have all these mannerisms in common, despite the fact they've been raised in different cultural environments etc. My daughter will say to people, I have a half-sister.

Laurie (separated lesbian couple)

However after a few years of friendly contact, the other family withdrew because they had made a decision that they would not tell their children (including subsequent children born through a different donor) that they were donor conceived. Laurie reported that her daughter, who had always known her 'conception story' found this difficult to understand and had been 'nagging' her recently to resume contact.

[I said] 'well look let's see if we can catch up with them, but you'll still have to not - you can't tell them, you can't tell your half-sister the nature of your relationship ... because otherwise you might lose the contact'.

Laurie (separated lesbian couple)

Thus while one family experienced this genetic link as establishing a quasi-familial relationship, the other family understood it to be a dimension in a friendship that ultimately held the potential to disrupt their familial and cultural conventions. 


\section{Passive Registers and Non Transparent Processes}

The passive operation of both voluntary government registers and clinic matching programs was the source of frustration for several interviewees. Scoot, who was already in contact with her donor, wanted another recipient family alerted to the fact that she was on the formal voluntary register in her state so that they could negotiate the possibility of early contact:

the Act ... says where both parties consent it's possible to have contact before the child reaches [maturity]. But then you go to the [authority] and they say, yeah, you have to join the registry and then if the donor joins then you can have earlier contact. But it's like, well that's not how the Act reads. It says if both parties are willing. Well, how can both parties be willing if you won't contact the other one and see if they're willing. You could contact that other party and say, are you willing to have earlier contact. But they won't do it.

Scoot (single mother)

Similarly, a number of interviewees who asked clinics to pass on a communication to the donor and other recipient families, respectively, were offered only 'passive' contact: that is, their letter would be placed on file and only offered to the other party if that person were themselves to contact the clinic seeking to initiate communication. Three interviewees were sufficiently discouraged by this process that they didn't in fact follow through with their own letter, such that even if the other party did initiate communication in the future, a connection would likely still not be made. In contrast, Scoot and Danielle were able to pass a request for communication through their clinic (to another recipient family and to the donor, respectively) which were declined by the recipient. Both volunteered that they were satisfied that the recipient, although not prepared to receive the communication, still 'knows we're here' and could make contact at a later point. These experiences provide an illustration of the benefits that an active register could provide.

Overall in the present study it appeared that clinics were more responsive to a wider range of requests for mediated communication than were formal voluntary registers, which were limited by the terms of their governing statutes as well as their more impersonalised mode of operation, for example their lack of counselling and support facilities (see also Crawshaw, 2010; 2011). On the negative side, clinic practices were also more diverse, non-transparent and unpredictable. Parents generally had no way of knowing what contact options their clinics supported until they asked, and these practices were also subject to change.

Within the study it was apparent that a number of clinics had altered their approach to voluntary disclosure of information and early contact in recent years. In the main, these changes were in response to patient requests and were moves towards more flexible practices around nonidentifying communication and voluntary early contact. However two interviewees reported that their clinics had offered the option of early contact (with the donor and with other recipient families, respectively) at the time of treatment but then subsequently stopped this practice. For the mothers who had anticipated the option of early contact, only to find out after their children were born that this was not possible, such changes were distressing and disappointing. 


\section{AN ACTIVE REGISTER}

The experience of the now abolished Infertility Treatment Authority ('ITA') in Victoria provides an instructive model of how an active voluntary register could operate in order to provide a middle path to accommodate the diverse unmet needs left by central registers. From 1988 centralised donor records were kept in Victoria but, until 1998 (when mandatory disclosure commenced) the law provided that identifying information about donors would only be released with their contemporaneous consent. Between 2006 (when the first offspring reached 18) and 2009 (when the authority was abolished), the ITA undertook 43 'outreaches' to donors at the request of offspring and parents, all but a few of whom agreed to the release of information. The authority developed specialist protocols for 'donor-linking' contact and counselling, and also undertook an extensive public education campaign to encourage greater awareness of and participation in, the voluntary registers (Parliament of Victoria, 2012: [6.1.1-6.1.3]; Johnson et al, 2012).

This process of outreach was enabled through the authority having access to confidential voter records in order to be able to verify contact details. Initial contact was made through a tactfully worded registered letter (in case a spouse or other person were to open it) and an invitation to telephone or email the sender. Most parties began with mediated contact, involving the exchange of letters through the authority, before some progressed on to direct contact, and some of them to later meeting in person (Parliament of Victoria, 2012: [6.1.2], [6.1.2.2]).

Before making contact with the donor, the counsellor would discuss the needs and expectations of the person seeking information, and would prepare information to convey to the donor. This included the person's reasons for requesting information, personal non-identifying information about themselves that they wished to share, and short and long term hopes in relation to information exchange. The person also prepared a list of questions for the counsellor, which the counsellor used in discussion with the donor in the event that he was reluctant to give consent, but was prepared to provide specific non-identifying information. This procedure allowed the donor to obtain an appreciation of the motivations behind the request for information, and provided sufficient information ... to contemplate how to respond (Parliament of Victoria, 2012: [6.1.2.1]).

The former ITA also provided a 'letter box' service as part of the process of outreach to donors as well as also broadly covering other recipient families desiring information or contact not available through the registers. This was described by one staff member as a 'beautifully simple' system of information exchange which allowed people to get to know each other over a period of time and make staged decisions about if and how they wanted the connection to develop (Parliament of Victoria, 2012 [6.1.3]). From 2010 the register was moved to a generalist government department and, while contact continued to be made via registered letter, the support services were not present (with much more limited counselling available only to the applicant contracted out to a postadoption agency) (Parliament of Victoria, 2012: [6.2.6]). One Victoria egg donor from the 1988-1997 period, who was recently approached for consent for her identifying details to be released, reported on the current process as follows: 
I got a registered letter [saying], 'We have some information that may be relevant to you'. Well, I knew what it was straight away. And so I contacted them, and then I had this kind of weird phone call with this person who said to me ... 'Did you donate to the IVF Program?' I said, 'Yes', and then she kind of said, 'Oh yes, well, the person who resulted is now seeking information and possible contact. So I'm going to send you some information about them. I'm going to ask you to fill in the form about whether you are prepared to have contact or not, and what level'. So it was actually that question about, you know, mobile number, email address; what are you prepared to give? ... They apparently gave that information back to ... this young [person], and it was up to [the person] to contact me. ... I waited quite some time, and then suddenly there was an email. ... I think that's really tough, that, you, you know, that young [donorconceived person] is left on [their] own to contact me. And then I'm potentially left on my own to manage it. ... you know, it's a big thing in your life to do this, and I think that particularly the young person deserves the support of someone professional around them, and possible support in organising, you know, at the very least an initial meeting or something like that. Because I think it's really hard (VARTA, 2013b: 71).

It is clear from the ITA reports of the process, and from detailed consideration of the impact of the lack of such support services in the Parliamentary Inquiries from both NSW and Victoria, that professional intermediation is a vital dimension of any active register. As the NSW Parliamentary Report notes, intermediation is about more than support, it is also a crucial aspect of informed consent as it provides the means for the donor to understand what it is they are consenting to in agreeing to identity release (NSW Parliament, 2013: [5.47]; this is particularly true for central registers, in which the donor granted consent 19 or more years earlier). If the donor is provided with a range of options including non-identifying ways to communicate then this gives a greater sense of control in the process.

The small amount of evidence available on the views of donors from the era of anonymity in the UK and Australia also suggests that they are more supportive of identity disclosure when there is intermediation and an opportunity for them to provide consent at the time the information is requested by a donor conceived person. In both the 2013 VARTA donor consultation and a 2007 UK survey even donors who were opposed to retrospective disclosure or who would not themselves join a voluntary register were willing to respond to a direct request for information (VARTA, 2013b; Crawshaw et al, 2007). In addition these and other studies from the US suggest that some donors also yearn for information and contact. ${ }^{25}$

As a response to the Parliament of Victoria Inquiry proposal to retrospectively remove donor anonymity, the government of Victoria initiated legislation ${ }^{26}$ to allow instead for access to identifying information from the era of anonymity only with the donor's contemporaneous consent in a process now overtly characterised to reflect counselling practice: 'donor-linking'. This legislation was introduced in late 2013 and, if passed, will commence by June 2015. Support services including counselling and intermediation will be reinstated to the specialist authority, VARTA. Counsellors will be required to provide a statement of the applicant's reasons for seeking information so that this can be passed on to the donor to enable them to make a decision about whether to consent. ${ }^{27}$ Once in place this model arguably offers the closest to the facilitative or 'stewardship' function proposed by the Nuffield Council, supporting consensual information exchange both retrospectively to address 
those conceived in the pre-disclosure era and prospectively to donor conception families, including those with minor children.

\section{CONCLUSION}

Identity disclosure rules in current assisted conception regimes appear to operate in ways that paradoxically act to both create and deny opportunities for the development of broader nontraditional kinship networks. Regulators increasingly mandate collection and timed release of records of donor identity, compel provision of counselling to gamete recipients about the importance of openness with children about the fact of donor conception, and even impose disclosure (for example through specifically marked birth records in the Australian state of Victoria). Yet at the same time that normative messages are communicated by the State and by fertility practitioners about the (potential) importance of genetic information in the formation of future children's self-identity, these same agencies in some instances refuse to facilitate communication between parties who have internalised such messages and, wishing to act upon them through early disclosure and discussion with their children, request varied forms of direct and indirect contact or other forms of non-identifying information about donors and offspring. Flat statutory disclosure regimes provide for particular kinds of information at set times to prescribed individuals, with little or no ability to adapt to more diverse requests. They also, arguably, fail to acknowledge the important role that parents play as custodians of information and of their children's current and future interests.

The parents interviewed in this research all consciously anticipated their child's future interests and needs concerning knowledge of their genetic relations, including donors and donor half siblings, irrespective of, and indeed sometimes in opposition to, their own view of the significance of such links. All expressed belief in the importance of open disclosure of donor conception and donor identity. In several instances mothers had pursued information exchange and/or contact in the face of unresponsive or inflexible legal regimes because of a deep concern to provide for children's future access to the fullest range of contact options. One interviewee, Sam, who had experience of treatment in both the UK and Australia tellingly described the rules she experienced as 'a system of withholding information from people'.

While the development of identity registers in Australia and the UK have been at the forefront of developments in this field, they have been premised upon the linear descendant genetic link as vital information to be prospectively released to young adults upon the attainment of majority. These registers leave a number of gaps: most notably requests for access to information from the era of anonymity; access to information prior to the age of majority and access to information on other offspring (at majority) or recipient families (for parents of minors). The significance of these lateral links has been largely overlooked by legal regimes, despite burgeoning sociological research on these links, a development that was reflected in the present study. Likewise the role that parents play in shaping, seeking and facilitating such lateral relationships either in making contact as family groups, or in seeking information on behalf of their children, is overlooked by disclosure regimes premised upon the donor-offspring dyad. While the development of a 'sufficient maturity' approach to 
information disclosure to offspring would be a welcome move towards a more flexible model, this still does not account for the fact that in some instances parents take action on their children's behalf. The high rate of participation of parents where they are permitted access to voluntary registers suggests that such registers would be more effective if they were broadened in scope.

The current formal voluntary registers in the UK and Australia have been dramatically underutilised, with low rates of registration and few matches made. Formal voluntary registers offer the hope of contact and information sharing, but very little prospect of its realisation and, as such, could be seen to contribute to an institutionalised 'limbo' that some donor conceived people, and donors, experience from assisted conception regimes. In contrast if active contact is made through an intermediary, even if identity disclosure is refused, there is at least a resolution (Bourne, 2013).

Inquiries in both countries have urged governments to better promote voluntary registers to raise public awareness, and to better resource them so that if participants do register they will be adequately supported in using them (Nuffield Council, 2013: [6.34], [6.38]; Parliament of Victoria, 2012: Recommendation 15, 18, 21, 22; NSW Parliament, 2013: Recommendations 1, 11, 12, 13). These proposals appear likely to be implemented in Victoria at least. Yet even Victoria, with the longest running voluntary register operative since 2001, specific public awareness and education campaigns from 2006 and, for much but not all of that time, specialist counselling, intermediation and support services, had by June 2013 only had 429 registrants out of a total pool of over 10,000 donors, parents and offspring, with a total of 85 matches made (VARTA, 2013a: 13; VARTA, 2013b: 8; Parliament of Victoria, 2012: 131). In other jurisdictions the numbers of registrants and matches are much lower. In comparison, the United States based informal 'Donor Sibling registry' claims to have 700 registrants from Australia, and 500 from the UK (Donor Sibling Registry, 2014) with almost 100 UK matches made by 2013 (Nuffield Council, 2013: [4.25]).

The Donor Sibling Registry and numerous smaller informal donor registers, both local and international, have sprung up on the internet allowing donor families and donors to search for matches regardless of legislative disclosure regimes and government held central registers (Hertz and Mattes, 2011). Such informal registers operate within varied conditions of moderation or mediation of contact and limited, if any, support services. It is suggested that they will continue to proliferate if formal registers fail to adapt to the needs and interests of donor and recipient families. At the same time, donor conceived people who have been denied access to information will continue to pursue retrospective identification of donors without their consent through litigation and law reform advocacy if no alternative is offered. In turn, it is possible that such agitation will depress the willingness of current and prospective donors to donate, if it leads to an atmosphere of uncertainty in the regulation of information disclosure in assisted conception.

The pathway offered by Victoria could serve as a useful model of formal voluntary registers to be remade as 'active' registers. Active voluntary registers offer a way to adapt current structures into a more flexible and responsive system capable of operating both prospectively and retrospectively, making contact with possible participants and offering intermediary services to establish and communicate expectations and to offer mediated contact, including contact without identity disclosure. I contend that this is a better solution than the current polarisation between an inability 
to access information for many on the one hand, or proposed alternatives such as retrospective identity disclosure without donors' consent, on the other.

The provision of such a service-driven model is justified through what the Nuffield Council poses as the role of the 'stewardship' State,

to facilitate what are seen as beneficial behaviours: to 'provide conditions', whether physical or social, that help and enable people in making their choices, while avoiding active intrusion in those choices unless there is very strong evidence to justify such intrusion for the benefit of others (Nuffield Council 2013: [5.67], emphasis in original; and see Millbank et al, 2013: 701, 709-711).

To date, State funding of the clinical and research dimensions of assisted reproduction have not been matched by comparable commitment to the 'social, emotional and legal dimensions of treatment' (Millbank et al, 2013: 711).

No disclosure regime can accommodate the diverse needs and wishes of all of the participants in donor conception. Further, it must be recalled that not all donor conceived people or their families will desire information or contact. However, the inflexible and non-responsive nature of government held registers to date means that they have not fulfilled their intended purpose. As Blyth et al note, policy in this field should 'maximise choice and opportunity for donor-conceived people' (Blyth et al, 2012: 788) and, I would add, for their families, within webs of kinship relationships that produce varied understandings of the significance of these relationships and consequent information needs.

\section{REFERENCES}

Allan, S. (2012a). A Cross-Jurisdictional Study of Regulatory Requirements and Practice Regarding the Recording of Donor Information and its Release to Donor Conceived People: A Report Prepared for the Winston Churchill Trust of Australia, available at http://www.churchilltrust.com.au/media/fellows/2011_Allan_Sonia.pdf (accessed 20 February 2014).

Allan, S. (2012b). 'Donor Identification "Kills Gamete Donation"? A Response', Human Reproduction 27 (12), 3380-4.

Australian Government (2012). Government Response to the Senate Legal and Constitutional Affairs References Committee Report, Donor Conception Practices in Australia.

Beeson, D., Jennings, P.K., and Kramer, W. (2011). 'Offspring Searching for their Sperm Donors: How Family Type Shapes the Process', Human Reproduction 26 (9), 2415-24.

Births, Deaths and Marriages Victoria (2012). 'Donor Treatment Registers', available at http://www.bdm.vic.gov.au/home/births/donor+treatment+registers/central+register/ (accessed 20 February 2014).

Blyth, E. (2012). 'Genes $r$ us? Making Sense of Genetic and Non-genetic Relationships Following Anonymous Donor Insemination', Reproductive BioMedicine Online 24 (7), 719-26. 
Blyth, E., Crawshaw, M., Frith, L. and Jones, C. (2012). 'Donor Conceived People's Views and Experiences of their Genetic Origins: A Critical Analysis of the Research Evidence', Journal of Law and Medicine 19 (4), 769-89..

Blyth E. and Frith, L. (2009). 'Donor-Conceived People's Access to Genetic and Biographical History: An Analysis of Provisions in Different Jurisdictions Permitting Disclosure of Donor Identity', International Journal of Law, Policy and the Family 23 (2), 174-91..

Blyth E. and Speirs, J. (2004). 'Meeting the Rights and Needs of Donor-Conceived People: The Contribution of a Voluntary Contact Register', Nordisk Sosialt Arbeid 24 (4), 318-30.

Bourne, K. (2013). Email to author of 19 December 2013, on file with author.

Bowman, M. (2013). Fertility Society of Australia Submission 14 to NSW Parliament Inquiry, available at

http://www.parliament.nsw.gov.au/prod/parlment/committee.nsf/0/7ADEA68D669F2BC9CA257B2 D0019C85E (accessed 20 February 2014).

Crawshaw, M., Blyth, E. and Daniels, K. (2007). 'Past Semen Donors' Views about the Use of a Voluntary Contact Register', Reproductive Medicine Online 14 (4), 411-17.

Crawshaw, M., and Marshall, L. (2008). 'Practice Experience of Running UK DonorLink, a Voluntary Information Exchange Register for Adults Related Through Donor Conception', Human Fertility 11 (4), 231-7.

Crawshaw, M. (2010). Submission No 156, 27 October 2010, Senate Inquiry.

Crawshaw, M. (2011). 'Report on Trip to Australia and New Zealand',University of York, 2011, available at http://www.york.ac.uk/media/spsw/documents/research-andpublications/CrawshawReportOnAustraliaNewZealandTripJanuary2011.pdf (accessed 20 February 2014).

Crawshaw, M., Gunter, C., Tidy, C., and Atherton, F. (2013). 'Working with Previously Anonymous Gamete Donors and Donor-Conceived Adults: Recent Practice Experiences of Running the DNABased Voluntary Information Exchange and Contact Register, UK DonorLink', Human Fertility 16 (1), 26-30.

Deutsche Welle (2013). 'Court rules sperm donors' children have right to know' DW, 6 February 2013, available at http://www.dw.de/court-rules-sperm-donors-children-have-right-to-know/a16580116 (accessed 20 February 2014).

Freeman, T., Jadva, V., Kramer, W., and Golombok, S. (2009). 'Gamete Donation: Parents' Experiences of Searching for their Child's Donor Siblings and Donor' Human Reproduction 24 (3), 505-16.

Government of Victoria (2013). Victorian Government Response, Inquiry into Access by DonorConceived People to Information about Donors, August 2013, available at http://www.parliament.vic.gov.au/images/stories/committees/lawrefrom/donorconceived/Response_to_Donor-conceived.pdf (accessed 20 February 2014). 
Grech, N. (2011). Submission No 67, 15 August 2011 Parliament of Victoria Inquiry, available at http://www.parliament.vic.gov.au/images/stories/committees/lawrefrom/iadcpiad/submissions/DC P67 - Narelle Grech.pdf (accessed 20 February 2014).

Hammarberg, K., Johnson, L., Bourne, K., Fisher, J. and Kirkman, M., (2014). 'Proposed Legislative Change Mandating Retrospective Release of Identifying Information: Consultation with Donors and Government Response', Human Reproduction 29 (2), 286-92.

Harris, M. (2014). Reproductive Technology Council of Western Australia, email to author of 22 January 2014 on file with author.

Hertz, R. and Mattes, J. (2011). 'Donor-Shared Siblings or Genetic Strangers: New Families, Clans and the Internet', Journal of Family Issues 32 (9), 1129-55.

Hertz, R., Nelson M. and Kramer, W. (2013). 'Donor Conceived Offspring Conceive of the Donor: The Relevance of Age, Awareness and Family Form', Social Science and Medicine 86, 52-65.

Human Fertilisation and Embryology Authority (2009a). Chair's Letter $\mathrm{CH}(09) 02$ 'Disclosure of Donor Codes' 19 March 2009, available at http://www.hfea.gov.uk/1836.html (accessed 20 February 2014).

Human Fertilisation and Embryology Authority (2009b). Disclosure of donor codes to gamete and embryo recipients: evaluation and review of HFEA policy, Authority Paper 486, 10 January 2009, available at http://www.hfea.gov.uk/docs/AM_Item_10_Jan09.pdf (accessed 20 February 2014).

Human Fertilisation and Embryology Authority (2011). Donation Review Annexes, 13 July 2011, available at http://www.hfea.gov.uk/docs/2011-07-13_Authority_paper_-_Donation_review__Annexes___FINAL.pdf (accessed 20 February 2014).

Human Fertilisation and Embryology Authority (2012). Human Fertilisation and Embryology Authority Policy on Collection, Confirmation and Publication of Register Data, available at http://www.hfea.gov.uk/docs/collectconfirmpublicatregisterdata.pdf_(accessed 20 February 2014).

Human Fertilisation and Embryology Authority (2013). 'Re-register as an Identifiable Donor', available at http://www.hfea.gov.uk/1973.html (accessed 20 February 2014).

Jadva, V., Freeman, T., Kramer W. and Golombok, S. (2010). 'Experiences of Offspring Searching for and Contacting Their Donor Siblings and Donor', Reproductive Biomedicine Online 20 (4), 523-32.

Jadva, V., Freeman, T., Kramer W. and Golombok, S. (2011). 'Sperm and Oocyte Donors' Experiences of Anonymous Donation and Subsequent Contact with their Donor Offspring', Human Reproduction $26(3), 638-45$.

Johnson, L., Bourne, K. and Hammarberg, K. (2012). 'Donor Conception Legislation in Victoria, Australia: The "Time to Tell" Campaign, Donor-Linking and Implications for Clinical Practice', Journal of Law and Medicine 19 (4), 803-19..

Leighton, K. (2013). 'To Criticise the Right to Know We Must Question the Value of Genetic Relatedness', American Journal of Bioethics 13 (5), 54-6.

Leighton, K. (2012). 'Addressing the Harms of Not Knowing One's Heredity: Lessons from Genealogical Bewilderment', Adoption and Culture 3, 63-106. 
McCallan, G., NSW Department of Health (2014) email to author 12 February 2014, on file with author.

Mahlstedt, P., LaBounty, K, and Kennedy, W. (2010). 'The Views of Adult Offspring of Sperm Donation: Essential Feedback for the Development of Ethical Guidelines Within the Practice of Assisted Reproductive Technology in the United States', Fertility and Sterility 93 (7), 2236-46.

Millbank, J., Karpin I., and Stuhmcke, A. (2013). 'Towards Facilitative Regulation of Assisted Reproductive Treatment in Australia', Journal of Law and Medicine 20 (4), 701-11.

National Health and Medical Research Council (2007). Ethical Guidelines on the Use of Reproductive Technology in Clinical Practice and Research, Canberra: NHMRC.

New South Wales Parliament Legislative Assembly (2013). Managing Donor Conception Information, Report 2/55 Committee on Law and Safety, October 2013. Sydney: NSW Parliament.

Nuffield Council on Bioethics (2013). Donor Conception: Ethical Aspects of Information Sharing, London: Nuffield Council.

O'Toole, E. (2013). HFEA email to author of 23 November 2013, on file with author.

Parliament of Victoria Law Reform Committee (2012). Inquiry into Access by Donor-Conceived People to Information About Donors - Final Report, Melbourne: Parliament of Victoria available at http://www.parliament.vic.gov.au/lawreform/article/1465 (accessed 20 February 2014).

Pennings, G. (2012). 'How to Kill Gamete Donation: Retrospective Legislation and Donor Anonymity', Human Reproduction 27 (10), 2881-5.

Readings, J., Blake, L., Casey, P., Jadva, V. and Golombok, S. (2011). 'Secrecy, Disclosure and Everything In-Between: Decisions of Parents of Children Conceived by Donor Insemination, Egg Donation and Surrogacy', Reproductive BioMedicine Online 22 (6), 485-95.

Reproductive Technology Accreditation Committee (2011). Advice to Units, Technical Bulletin 3, April 2011, available at http://www.fertilitysociety.com.au/wp-content/uploads/20110506-technical-bulletinnumber-3.pdf (accessed 20 February 2014).

Reproductive Technology Council of Western Australia (2013a). Annual Report 2012-13, Perth: RTC.

Reproductive Technology Council of Western Australia (2013b). 'Fact Sheet 7: Access to Information', available at http://www.rtc.org.au/donor/docs/7-Access-to-information.pdf (accessed 20 February 2014).

Russell, H. (2013). Victorian Registry of Births, Deaths and Marriages, email to author, 22 November 2013, on file with author.

Scheib, J. and Ruby, A. (2008). 'Contact Among Families Who Share the Same Sperm Donor' Fertility and Sterility 90 (1), 33-43.

Senate Legal and Constitutional Affairs References Committee (2011). Donor Conception Practices in Australia: Report, Canberra: Commonwealth of Australia, available at http://www.aph.gov.au/Parliamentary_Business/Committees/Senate/Legal_and_Constitutional_Aff airs/Completed\%20inquiries/2010-13/donorconception/index (accessed 20 February 2014). 
Smith, L. (2013). 'Tangling the web of Legal Parenthood: Legal Responses to the use of Known Donors in Lesbian Parenting Arrangements', Legal Studies 33 (3), 355-81.

Special Issue: Law, Policy and Practice Concerning Stored Embryos in Assisted Reproduction (2013). Journal of Law and Medicine 20 (4), 701-11, 759-830.

Thompson, P. (2013). 'Human Fertilisation and Embryology Authority, Submission 24 to NSW Inquiry', February 2013, available at http://www.parliament.nsw.gov.au/prod/parlment/committee.nsf/0/088f2c05b1604bf7ca257b2d0 01b98ab/\$FILE/Submission\%2024\%20-

\%20Human\%20Fertilisation\%20and\%20Embryology\%20Authority.pdf (accessed 20 February 2014).

Tomazin, F. (2013). "'Suddenly she's there": Daughter and Donor Dad United', The Age (Victoria), 17 March 2013.

Turner (Springfield), K. (2011). 'Submission 50' (11 August 2011) Parliament of Victoria Inquiry, available at http://www.parliament.vic.gov.au/images/stories/committees/lawrefrom/iadcpiad/submissions/DC P50_-_Kimberley_Turner_Springfield.pdf (accessed 20 February 2014).

VARTA (2013a). Annual Report 2013, Melbourne: VARTA.

VARTA (2013b). Consultation with Donors who Donated Gametes in Victoria, Australia before 1998: Access by Donor-Conceived People to Information about Donors, Report to the Victorian Government, Melbourne: VARTA, available at http://www.varta.org.au/donor-consultation/ (accessed 20 February 2014).

Victorian Law Reform Commission (2007). Assisted Reproductive Technology \& Adoption, Final Report, Melbourne: VLRC.

Witjens, L. (2013). Donor Conceived Register, email to author of 20 December 2013, on file with author.

Zanghellini, A. (2012). 'A v B and C [2012] EWCA Civ 285: Heteronormativity, Poly-parenting, and the Homo-nuclear family', Child and Family Law Quarterly, 24 (4): 475-86.

\section{NOTES}

${ }^{1}$ Human Fertilisation and Embryology Act 2008 (UK) s 14(6C) licensing condition (a); National Health and Medical Research Council, 2007, [6.1.2].

${ }^{2}$ Springfield v Registrar of Births, Deaths and Marriages (General) [2011] VCAT 130 (10 February 2011).

${ }^{3}$ Eg Pratten v British Columbia (2011) BCSC 656; (2012) 12 BCCA 480; Rose v Secretary of State for Health and the HFEA [2002] EWHC 1593. 'Court rules sperm donors' children have right to know' Deutsche Welle, 6 February 2013 at <http://www.dw.de/court-rules-sperm-donors-children-have-right-to-know/a-16580116>.

${ }^{4}$ Recommendation 4 allowed for contact vetos to be lodged by donors, which would have to be renewed by them every 5 years (Parliament of Victoria Report, Rec 4). 
${ }^{5}$ Assisted Reproductive Technology Further Amendment Bill 2013 (Vic). Introduced into the Legislative Assembly 10 December 2013. See also Government of Victoria, Assisted Reproductive Technology Further Amendment Bill 2013, Explanatory Memorandum (2013).

${ }^{6}$ The study was undertaken by three investigators from UTS: Law, Jenni Millbank, Anita Stuhmcke and Isabel Karpin with the assistance of Eloise Chandler. Ethics approval to conduct this research was obtained through the University of Technology, Sydney Human Research Ethics Committee (UTS HREC Reference Number: 2009262A). For findings related to the broader study, see Special Issue: Law, Policy and Practice Concerning Stored Embryos in Assisted Reproduction (2013) 20 Journal of Law and Medicine 701-711, 759-830. All interviewees are represented by a pseudonym.

${ }^{7}$ Human Fertilisation and Embryology Authority (Disclosure of Information) Regulations 2004 (UK); see also HFEA, 2012.

${ }^{8}$ Thus for conceptions from 1988-1997 the donor's identity is only released with their agreement at the time of the offspring request: this is discussed in detail later in this paper. Note that parents and descendants of offspring can also request identifying information under the central register but only with the consent of the donor. See Births, Deaths and Marriages Victoria, Donor Treatment Registers, at <http://www.bdm.vic.gov.au/home/births/donor+treatment+registers/central+register/>.

${ }^{9}$ Human Reproductive Technology Act 1991 (WA); Human Reproductive Technology (Licenses and Registers) Regulations 1993 (WA); Human Reproductive Technology Directions 2004 (WA).

${ }^{10}$ Assisted Reproductive Technology Act 2007 (NSW); Assisted Reproductive Technology Regulations 2009 (NSW). See NSW Government, Department of Health, at <http://www.health.nsw.gov.au/art/pages/default.aspx>.

${ }^{11}$ NHMRC, Ethical Guidelines, 2007: [6.1]. South Australian legislation to enable a donor register passed in 2009 but it has remained unimplemented to date. These legislative regimes differ from the obligations imposed by national ethics guidelines in that the records are held in a central government register rather than in individual clinics: see for an overview of Australian jurisdictions Allan, 2012a: 49-52.

${ }^{12}$ See eg Parliament of Victoria, 2012: [3.2.2] on the divergence in record keeping and in clinic and government held records in terms of whether they will attempt contact with donors to seek consent for identification.

${ }^{13}$ See Human Reproductive Technology Act 1991 (WA), s. 49(2b).

${ }^{14}$ See Human Fertilisation and Embryology Act 2008 (UK), s. 31;Assisted Reproductive Technology Act 2007 (NSW), ss. 37(1), 4(1); Assisted Reproductive Treatment Act 2008 (Vic), s. 59(1)(a)(i). This is also the age set by national ethical guidelines for release of information by clinics in states where there is no legislated disclosure regime: NHMRC Ethical Guidelines (2007) 6.11.

${ }^{15}$ Human Reproductive Technology Act 1991 (WA), s. 49(2c).

${ }^{16}$ Assisted Reproductive Treatment Act 2008 (Vic), s. 59(a)(ii).

${ }^{17}$ Assisted Reproductive Treatment Act 2008 (Vic), s.58(1)(a).

${ }^{18}$ Assisted Reproductive Technology Act 2007 (NSW) s. 38(1)(c).

${ }^{19}$ HFEA, 'Re-register as an Identifiable Donor' at <http://www.hfea.gov.uk/1973.html>. As at February 2013, 120 donors had reregistered: see Thompson, 2013. 
${ }^{20}$ Assisted Reproductive Technology Act 2007 (NSW); Assisted Reproductive Technology Regulations 2009 (NSW).

${ }^{21}$ Assisted Reproductive Treatment Act 2008 (Vic) Part 7. This repealed and replaced the earlier Infertility Treatment Act 1995 (Vic). See Births, Deaths and Marriages Victoria, Donor Treatment Registers, at <http://www.bdm.vic.gov.au/home/births/donor+treatment+registers/voluntary+register/>.

${ }^{22}$ At that time the Central register had 2215 donors and 5903 offspring recorded, meaning that there were up to 5900 recipient mothers (although some would have more than one donor conceived child) and up to that number of second parents as well, ie upwards of 10,000 participants from donor conception on the central register who could potentially utilise the voluntary register. In addition there would be many more potential registrants from conceptions which pre-dated the 1988 central register.

${ }^{23}$ There were 79 matches to December 2012: VARTA, 2013b: 8. Six matches took place in 2013: VARTA, 2013a: 13.

${ }^{24}$ Of 23 matches in this period, 13 involved matches between donor and parent, 5 were parent-parent matches and 5 were donor-offspring matches: Russell, 2013.

${ }^{25}$ See the extended quotations in the Donor Consultation, 2013, eg Jack B, 'A few years ago, I got an email ... which said, "There are [more than 20] children."... thought, "Great. When they turn 18 ... I expect some of them will get in touch". And, you know, quietly I was thinking, "Well, I wonder what they'll be like." And then there was a resounding silence, so you know, I didn't hear anything about it for years. ... I've sort of come to terms with it, I suppose, but I'm a bit sad, if I'm honest', VARTA, 2013b: 37; and also Bruce 34, James, 35, Noel, 35, Evan, 38. See also Jadva et al, 2011.

${ }^{26}$ Assisted Reproductive Treatment Further Amendment Bill 2013 (Vic), cl. 21. The Bill also extends access to non-identifying information about the donor and other offspring (sex, month and year of birth), grants donors from earlier eras a statutory right to such non-identifying information and provides for the exchange of information about serious genetic or hereditary conditions: see Assisted Reproductive Treatment Further Amendment Bill 2013, Second Reading Speech, Parliament of Victoria, Legislative Assembly 11 December 2013, 64 (Mary Wooldridge).

${ }^{27}$ Assisted Reproductive Treatment Further Amendment Bill 2013 (Vic), cl. 15 proposed s. 67A(4). Although note that VARTA will be providing counselling only to the applicant and not to the donor, such that this is a partial version of intermediary support. 